\title{
Maan kosteus herukan ja mansikan viljelyssä
}

\author{
Kalle Hoppula $^{1)}$, Tapio Salo ${ }^{2)}$ ja Janne Pulkkinen ${ }^{3)}$ \\ 1)MTT puutarhatuotanto,Toivonlinnantie 518,21500 Piikkiö, kalle.hoppula@mtt.fi \\ 2) MTT maaperä ja ympäristö, E-talo, 31600 Jokioinen, tapio.salo@mtt.fi \\ 3) Kemira GrowHow Oy, PL 900,00181 Helsinki, janne.pulkkinen@kemira-growhow.com
}

\begin{abstract}
Johdanto
Mansikan ja mustaherukan satotasot vaihtelevat huomattavasti vuosittain ja oloissamme saavutettavissa olevan satopotentiaalin ja toteutuneen sadon välillä on usein merkittävä "satoaukko". Veden riittävä saatavuus kasveille on perustekijöitä pyrittäessä lähelle satopotentiaalia. Tihkukastelun käyttöönotto marjatiloilla on olennaisesti helpottanut kastelumahdollisuuksia ja siksi kastelusuositukset olisi ajankohtaistettava uutta tekniikkaa vastaavaksi.

MTT puutarhatuotannossa Piikkiössä oli vuosina 2001-2003 tutkimusprojekti "Tihkukastelu ja kastelulannoitus puutarhakasvien sadon varmistajana avomaalla", jossa tutkittiin avomaankurkun, mansikan, mustaherukan ja vadelman kastelua ja lannoitusta. Tässä esitelmässä käsitellään tutkimusprojektista saatuja tuloksia maan kosteuden merkityksestä mansikan ja mustaherukan sadontuottoon.

Tutkimuksen käytännöllisenä tavoitteena oli määrittää yllämainittujen kasvien kastelutarve sekä luoda tihkukastelun ja tensiometrin käyttöön perustuvat kasteluohjeet viljelijöille. Kastelutarpeen arvioinnissa päädyttiin käyttämään maan vesipotentiaalia mittavaa tensiometriä, koska tämä on menetelmänä edullinen ja yksinkertainen sekä soveltuu käytettäväksi maatiloilla. Tensiometri kertoo sen voiman, jonka kasvin juurten on voitettava saadakseen vettä käyttöönsä, ja toimii siis ikään kuin keinojuurena. Mitä lähempänä nollaa $(0 \mathrm{hPa})$ tensiometrin lukema on, sitä löyhemmin vesi on kiinnittynyt maahan ja sitä enemmän vettä on siis käytettävissä. Kenttäkapasiteetin arvo hietamaalla on tensiometrillä mitattuna noin $-100 \mathrm{hPa}$.
\end{abstract}

\section{Aineisto ja menetelmät}

Tutkimus toteutettiin MTT puutarhatuotannossa Piikkiössä vuosina 2001-2003. Mustaherukalla ('Mortti') ja mansikalla ('Bounty') kokeiltiin maan kosteuden osalta kolmea erilaista käsittelyä, 1) kasteluraja $-150 \mathrm{hPa}, 2$ ) kasteluraja $-300 \mathrm{hPa}$ ja 3) kasteluraja $-600 \mathrm{hPa}$. Mustaherukalla oli samassa koejärjestelyssä mukana toisena faktorina kahden eri lannoitustavan, rakeisen lannoituksen ja kastelulannoituksen, vertailu. Tässä ei kuitenkaan käsitellä tuloksia lannoitustavan vaikutuksen osalta.

Mustaherukan taimet istutettiin 17.-18.5.2001 ja mansikan taimet 20.6.2001. Kaikki taimet istutettiin mustaan muoviin ja mansikalla käytettiin tihkuletkua T-Tape TSX 508-30-340 (30 cm suutinväli, 3,4 1/h/m) ja mustaherukalla tihkuletkua Tipaz (40 cm suutinväli, 5,0 1/h/m). Mustaherukalla riviväli oli $3,5 \mathrm{~m}$ ja taimiväli $0,5 \mathrm{~m}(5700 \mathrm{kpl} / \mathrm{ha})$. Mansikan taimet istutettiin paririviin $1,5 \mathrm{~m}$ rivivälillä ja $0,33 \mathrm{~m}$ taimivälillä (40000 kpl/ha). Maaperä oli multavaa hienoa hietaa. Koealueella oli kummallakin kasvilajilla neljä lohkoa, joihin käsittelyt oli satunnaistettu. Mansikalla yhdessä koeruudussa oli 34 tainta, mustaherukalla seitsemän.

Mansikalla lannoitus toteutettiin kastelulannoituksena, N 60 kg/ha/vuosi, P 15 kg/ha/vuosi ja K $80 \mathrm{~kg} / \mathrm{ha} /$ vuosi. Mustaherukalla sekä kokeen kastelulannoitettua osaa että rakeisilla lannoitteilla lannoitettua osaa lannoitettiin N $25 \mathrm{~kg} / \mathrm{ha} / \mathrm{vuosi}$, P $10 \mathrm{~kg} / \mathrm{ha} /$ vuosi ja K $60 \mathrm{~kg} / \mathrm{ha} / \mathrm{vuosi}$.

Maan kosteutta mitattiin tensiometrillä (Nieuwkoop TM-93, $30 \mathrm{~cm}$ mittausputkilla). Kastelu käynnistettiin kussakin käsittelyssä ensimmäisen tensiometrin neljästä ylitettyä kastelurajan ja maa kasteltiin tällöin tasolle $-50 \ldots-100 \mathrm{hPa}$ saakka. Eri käsittelyjen keskimääräiset maan kosteudet ja niiden keskihajonnat on esitetty Taulukossa 1 ja eri käsittelyjen kastelumäärät Taulukossa 2.

Sadevesien vaikutus maankosteuteen pyrittiin mansikalla minimoimaan sijoittamalla koe kahteen kevytrakenteiseen kausihuoneeseen. Mustaherukkakoealueella ei vuonna 2001 sadesuojausta ollut lainkaan, mutta kasvukauden 2002 ajaksi koko alueelle levitettiin maan pintaan tiivis muovi, joka edelleen peitettiin hakkeella. Tämän toivottiin estävän sateiden vaikutuksen maan kosteuteen ja osittain ratkaisu auttoikin. Kasvukaudella 2003 tästä ratkaisusta luovuttiin, koska se oli normaalista viljelykäytännöstä selvästi poikkeava ja toisaalta myös rajoitti pintamaan kuivumista estämällä haihdutuksen.

Mansikalta ja mustaherukalta korjattiin satoa vuosina 2002 ja 2003 . Mansikalla sadonkorjuisiin käytettiin kustakin ruudusta kuusi tainta ja mustaherukalla yksi taimi. Mansikalla sadonkorjuun yhtey- 
dessä marjoista lajiteltiin erikseen niin sanottu kauppakelpoinen sato, johon kuuluivat hyvälaatuiset halkaisijaltaan yli $22 \mathrm{~mm}$ olevat marjat. Kunakin sadonkorjuupäivänä sadot punnittiin ja marjojen lukumäärät laskettiin. Mustaherukalla ainoastaan punnittiin kokonaissato sekä laskettiin keskimääräinen marjakoko satunnaisotantana tehdyn sadan marjan painon perusteella. Mixed.

Tulokset analysoitiin varianssianalyysillä käyttäen SAS 8.01 -tilasto-ohjelmiston proseduuria

Taulukko 1. Keskimääräinen maan kosteus (hPa) ja sen keskihajonta (hPa) eri käsittelyissä.

\begin{tabular}{lllll}
\hline 2001 & & & & \\
Kasvilaji & Syvyys & $-150 \mathrm{hPa}$ & $-300 \mathrm{hPa}$ & $-600 \mathrm{hPa}$ \\
\hline Mansikka & $15 \mathrm{~cm}$ & $-90 \pm 23$ & $-104 \pm 46$ & $-129 \pm 107$ \\
Mansikka & $30 \mathrm{~cm}$ & ei mitattu & ei mitattu & ei mitattu \\
Mustaherukka & $20 \mathrm{~cm}$ & $-152 \pm 72$ & $-173 \pm 108$ & $-214 \pm 159$ \\
Mustaherukka & $40 \mathrm{~cm}$ & $-122 \pm 21$ & $-125 \pm 26$ & $-135 \pm 36$ \\
\hline 2002 & & & & \\
Kasvilaji & Syvyys & $-150 \mathrm{hPa}$ & $-300 \mathrm{hPa}$ & $-600 \mathrm{hPa}$ \\
Mansikka & $15 \mathrm{~cm}$ & $-103 \pm 38$ & $-117 \pm 67$ & $-195 \pm 148$ \\
Mansikka & $30 \mathrm{~cm}$ & $-96 \pm 33$ & $-115 \pm 77$ & $-221 \pm 164$ \\
Mustaherukka & $20 \mathrm{~cm}$ & $-215 \pm 102$ & $-253 \pm 137$ & $-270 \pm 141$ \\
Mustaherukka & $40 \mathrm{~cm}$ & $-123 \pm 10$ & $-129 \pm 29$ & $-155 \pm 49$ \\
& & & & \\
\hline 2003 & & & & \\
Kasvilaji & Syvyys & $-150 \mathrm{hPa}$ & $-300 \mathrm{hPa}$ & $-600 \mathrm{hPa}$ \\
Mansikka & $15 \mathrm{~cm}$ & $-100 \pm 19$ & $-102 \pm 27$ & $-118 \pm 34$ \\
Mansikka & $30 \mathrm{~cm}$ & $-84 \pm 14$ & $-82 \pm 15$ & $-94 \pm 22$ \\
Mustaherukka & $20 \mathrm{~cm}$ & $-151 \pm 63$ & $-207 \pm 133$ & $-206 \pm 116$ \\
Mustaherukka & $40 \mathrm{~cm}$ & $-125 \pm 17$ & $-143 \pm 43$ & $-206 \pm 129$ \\
& & & & \\
\hline
\end{tabular}

Taulukko 2. Kastelumäärät. Kastelukertojen lukumäärä x keskimääräinen kertakastelu 1/taimi.

\begin{tabular}{llll}
\hline Mansikka & $-150 \mathrm{hPa}$ & $-300 \mathrm{hPa}$ & $-600 \mathrm{hPa}$ \\
\hline 2001 & $3 \times 1,4$ & $2 \times 2,6$ & $2 \times 5,2$ \\
2002 & $13 \times 1,7$ & $9 \times 3,6$ & $5 \times 1,6$ \\
2003 & $5 \times 1,3$ & $5 \times 1,3$ & $5 \times 1,3$ \\
& & & \\
\hline Mustaherukka & $-150 \mathrm{hPa}$ & $-300 \mathrm{hPa}$ & $-600 \mathrm{hPa}$ \\
\hline 2001 & $24 \times 4,3$ & $14 \times 10,2$ & $4 \times 15,3$ \\
2002 & $49 \times 4,3$ & $36 \times 10,6$ & $5 \times 20,7$ \\
2003 & $39 \times 4,3$ & $19 \times 10,4$ & $3 \times 13,1$ \\
\hline
\end{tabular}

\section{Tulokset ja tulosten tarkastelu}

Käsittelyjen väliset erot eivät olleet missään tapauksessa tilastollisesti merkitseviä. Molemmilla kasveilla vuonna 2002 maan kosteuden lisääminen vaikutti kuitenkin kannattavan. Mansikalla kauppakelpoisen sadon määrä nousi maan kosteuden noustessa ja sama ilmiö oli havaittavissa mustaherukallakin. Mansikalla myös keskimääräinen marjakoko oli sitä suurempi, mitä kosteampi maa oli. Mustaherukalla maan kosteus ei vaikuttanut selvästi marjakokoon. Molempien kasvilajien osalta satotulokset on esitetty Taulukossa 3.

Talvella 2002-2003 mansikan taimet saivat pahoja talvivaurioita, jonka vuoksi niiden sadontuottokyky kasvukaudella 2003 oli heikko. Silmämääräisesti arvioituna eri käsittelyjen välillä ei ollut eroja talvehtimisessa. Kasvukaudella 2003 taimien vedenkulutus oli niin pieni, että käsittelyjen välille ei pystytty luomaan eroja maan kosteuden suhteen ja myöskään satotasoissa ei ollut juurikaan eroja. Kas- 
telurajoja ei missään käsittelyssä saavutettu missään vaiheessa kasvukautta ja kasvit saivat ainoastaan kastelulannoituksen edellyttämät kastelut.

Maan kosteus ei vaikuttanut mustaherukan vuoden 2003 satotasoihin tai marjakokoon. Mustaherukalla $-300 \mathrm{hPa}$ ja $-600 \mathrm{hPa}$ kastelurajakäsittelyjen välille ei muodostunut eroa maan kosteudessa, vaikka kyseisten käsittelyjen saamat kastelumäärät poikkesivat toisistaan huomattavasti.

Tämän tutkimuksen tulokset eivät ole ristiriidassa mansikalla aiemmista tutkimuksista saatujen tulosten kanssa. Krüger ym. (2002) vertasivat kastelurajoja $-200 \mathrm{hPa}$ ja $-300 \mathrm{hPa}$ ja havaitsivat, että näiden kahden kastelurajan välillä ei ollut eroa mansikan sadontuottokyvyssä. Toisaalta Evenhuis ja Alblas (2002) havaitsivat kastelurajoilla $-150 \mathrm{hPa}$ ja $-200 \mathrm{hPa}$ satovasteen olevan parempi kuin kastelurajalla $-300 \mathrm{hPa}$. Clarkin ym. (1996) tutkimuksessa kastelurajojen $-50 \mathrm{hPa},-100 \mathrm{hPa}$ ja $-150 \mathrm{hPa}$ välillä ei ollut eroja. Tahvonen ym. (2001) vertasivat kahta maan kosteuden vaihteluväliä, $-100 \ldots-200$ $\mathrm{hPa}$ ja $-200 \ldots-700 \mathrm{hPa}$, ja havaitsivat satotasojen olevan kosteampana pysyneessä maassa parempia kuin kuivemmassa vaihtoehdossa.

On mahdollista, että mansikan optimaalinen maan kosteus vaihtelee kasvupaikan ympäristöolosuhteiden sekä taimen kehitysvaiheen mukaan. Vaikuttaa kuitenkin siltä, että optimisatojen saavuttamiseksi maan kosteuden olisi oltava vähintään noin $-150 \mathrm{hPa}$.

Mustaherukalla aiemmissa maan vesipotentiaalin vaikutusta sadontuottoon käsitelleissä tutkimuksissa maan kosteuden vaihtelut ovat olleet huomattavasti suurempia kuin tässä tutkimuksessa. Kongsrud (1969) vertasi kuutta eri kastelurajaa väleillä $-500 \mathrm{hPa} . . .-2500 \mathrm{hPa}$ ja havaitsi vedensaannin parantuessa myös satotasojen nousevan. Goode ja Hyrycz (1970) vertasivat kahta eri kastelurajaa, $-270 \mathrm{hPa}$ ja $-670 \mathrm{hPa}$, ja havaitsivat myös satotasojen nousevan vedensaannin parantuessa. Tässä tutkimuksessa maan kosteuden vaihtelut mustaherukalla olivat näihin verrattuna vähäisiä ja ilmeisesti siitä johtuen selviä eroja eri käsittelyjen välille ei muodostunut.

Muualla tehdyissä tutkimuksissa tensiometrin käyttökelpoisuudesta maan kosteuden mittarina on vaihtelevia tuloksia. Krügerin ym. (2002) mukaan kastelu matemaattisen ilmastomallin perusteella antaa tensiometrin perusteella tehtävää kastelua paremman satovasteen, mutta toisaalta Evenhuis ja Alblas (2002) totesivat tutkimuksessaan tensiometrin soveltuvan matemaattista ilmasto- ja maaperämallia paremmin kastelutarpeen määrittäjäksi.

Taulukko 3. Mansikan ja mustaherukan sadot 2002 ja 2003.

\begin{tabular}{llll}
\hline Mansikka 2002 & $-150 \mathrm{hPa}$ & $-300 \mathrm{hPa}$ & $-600 \mathrm{hPa}$ \\
\hline Kokonaissato g/taimi & 750 & 659 & 660 \\
Kauppakelp. sato g/taimi & 561 & 509 & 474 \\
Marjakoko g/kpl & 7,6 & 7,3 & 6,8 \\
& & & \\
\hline Mansikka 2003 & $-150 \mathrm{hPa}$ & $-300 \mathrm{hPa}$ & $-600 \mathrm{hPa}$ \\
\hline Kokonaissato g/taimi & 105 & 100 & 133 \\
Kauppakelp. sato g/taimi & 81 & 70 & 98 \\
Marjakoko g/kpl & 5,1 & 4,6 & 5,0 \\
\hline Mustaherukka 2002 & $-150 \mathrm{hPa}$ & $-300 \mathrm{hPa}$ & $-600 \mathrm{hPa}$ \\
\hline Kokonaissato g/taimi & 571 & 495 & 491 \\
Marjakoko g/kpl & 0,95 & 0,98 & 0,88 \\
& & & \\
\hline Mustaherukka2003 & $-150 \mathrm{hPa}$ & $-300 \mathrm{hPa}$ & $-600 \mathrm{hPa}$ \\
Kokonaissato g/taimi & 1755 & 1822 & 1644 \\
Marjakoko g/kpl & 0,79 & 0,83 & 0,83 \\
\hline
\end{tabular}

\section{Johtopäätökset}

Tutkimuksessa ei saatu varmoja tuloksia maan kosteuden vaikutuksesta mansikan ja mustaherukan sadontuottoon. Luultavasti kuitenkin molemmat kasvilajit hyötyvät tasaisesta ja runsaasta vedensaannista. Tämän sekä aiempien tutkimuksen tulosten perusteella on syytä olettaa, että hietamailla, joilla mansikkaa Suomessa yleisimmin viljellään, optimaalinen maan kosteus on $0 \ldots-150 \mathrm{hPa}$ ja voimakkaat kosteuden vaihtelut heikentävät mansikan sadontuottokykyä. Mustaherukalla voimakasta maan 
kosteuden vaihtelua ei tutkimuksessa onnistuttu luomaan ja siksi tutkimustuloksista ei mustaherukan osalta pystytä tekemään johtopäätöksiä. Aiempien tutkimusten perusteella mustaherukka kuitenkin hyötyy runsaasta maan kosteudesta.

Tutkimuksessa havaittiin, että kastelu kannattaa mitoittaa kasvin vedenkulutuksen mukaan. Mansikalla vedenkulutus oli ensimmäisenä satovuonna 2002 selvästi suurempi kuin tutkimuksen kahtena muuna vuonna. Istutusvuoden 2001 kastelumäärät olivat vähäisiä, koska taimet olivat nuoria ja iästään johtuen vielä pienikokoisia. Toisen satovuoden 2003 kastelumäärät olivat vähäisiä, koska taimet kärsivät pahoja talvivaurioita edeltävänä talvena ja siksi niiden kasvu- ja sadontuottokyky oli heikko.

Kastelutarve kannattaa määrittää maan kosteuden mittaustulosten perusteella, koska taimen vedenkulutus vaihtelee huomattavasti sen satopotentiaalista ja kasvuvaiheesta sekä ympäristötekijöistä johtuen.

\section{Kirjallisuus}

Clark, G.A., Albregts, E.E., Stanley, C.D., Smajstrla, A.G. \& Zazueta, F.S. 1996. Water requirements and crop coefficients of drip-irrigated strawberry plants. Transactions of the ASAE 39(3): 905-913.

Evenhuis, A. \& Alblas, J. 2002. Irrigation of strawberries by the use of decision support systems. Acta Horticulturae 567: 475-478.

Goode, J.E. \& Hyrycz, K.J. 1970. The response of black currants to different soil moisture conditions and two levels of nitrogenous fertilizer. Journal of Horticultural Science 45:379-391.

Kongsrud, K.L. 1969. Effects of soil moisture tension on growth and yield in black currants and apples. Acta agriculturae scandinavica 19: 245-257.

Krüger, E., Schmidt, G. \& Brückner, U. 1999. Scheduling strawberry irrigation based upon tensiometer measurement and a climatic water balance model. Scientia Horticulturae 81: 409-424.

Krüger, E., Schmidt, G. \& Rasim, S. 2002. Effect of irrigation on yield, fruit size and firmness of strawberry cv. Elsanta. Acta Horticulturae 567: 471-474.

Tahvonen, R., Hoppula, K., Ylämäki, A. \& Pulkkinen, J. 2001. Mansikan tarkennettu lannoitus ja kastelu. Maatalouden tutkimuskeskuksen julkaisuja Sarja A 91: 7-13. 